-har 291968

IN-REACTOR THERMIONIC CONVERTER TESTING EXPERIENCE AT GENERAL ELECTRIC

J. E. VanHoomissen

D. J. Holtslag
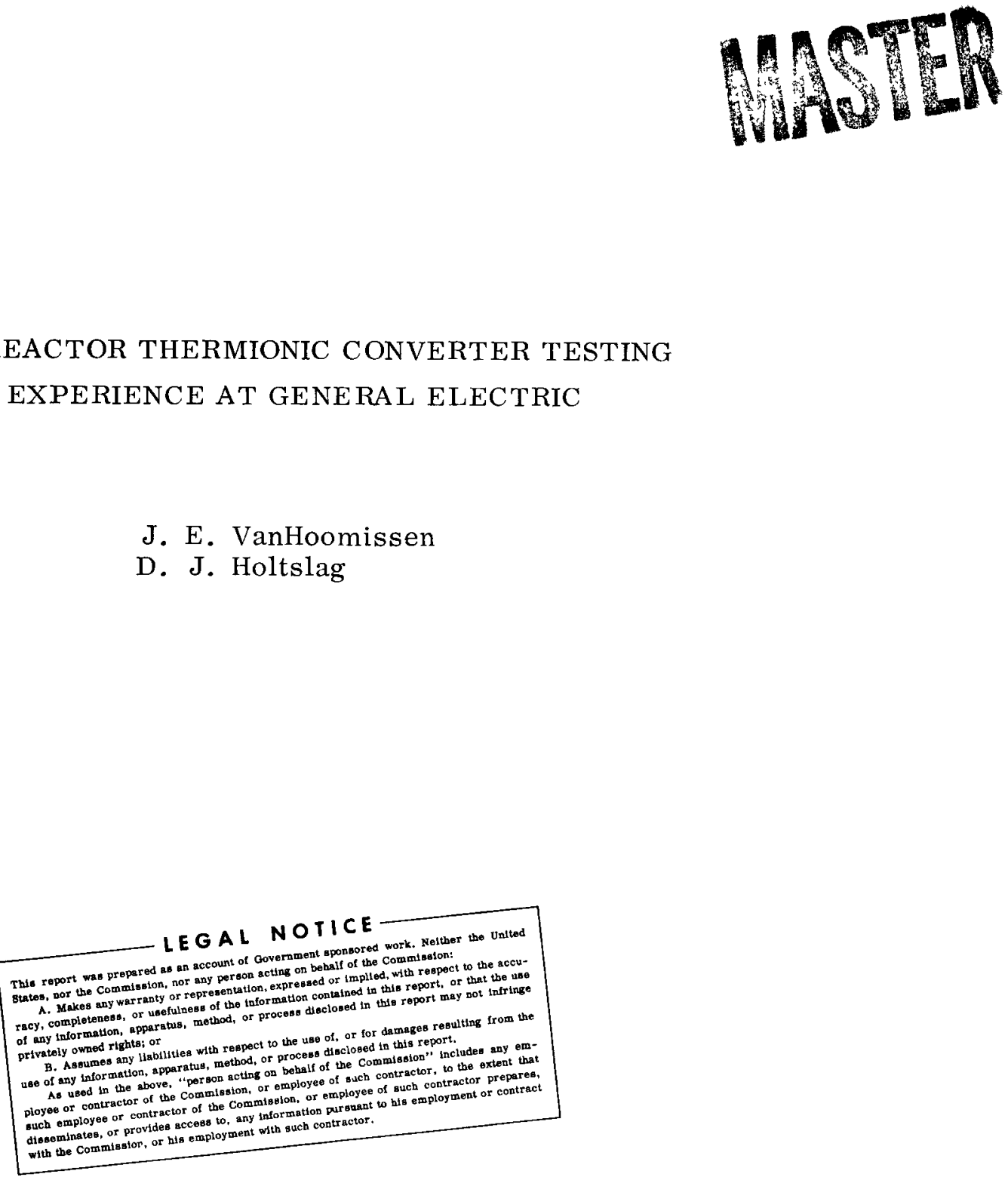

Nuclear Thermionic Power Operation

General Electric Company

Pleasanton, California

United States of America 


\section{DISCLAIMER}

This report was prepared as an account of work sponsored by an agency of the United States Government. Neither the United States Government nor any agency Thereof, nor any of their employees, makes any warranty, express or implied, or assumes any legal liability or responsibility for the accuracy, completeness, or usefulness of any information, apparatus, product, or process disclosed, or represents that its use would not infringe privately owned rights. Reference herein to any specific commercial product, process, or service by trade name, trademark, manufacturer, or otherwise does not necessarily constitute or imply its endorsement, recommendation, or favoring by the United States Government or any agency thereof. The views and opinions of authors expressed herein do not necessarily state or reflect those of the United States Government or any agency thereof. 


\section{DISCLAIMER}

Portions of this document may be illegible in electronic image products. Images are produced from the best available original document. 


\title{
IN-REACTOR THERMIONIC CONVERTER TESTING EXPERIENCE AT GENERAL ELECTRIC*
}

\author{
J.E. VanHoomissen and D.J. Holtslag \\ General Electric Company, Pleasanton, California \\ United States of America
}

\begin{abstract}
The design and testing of two single-cell fission powered thermionic converters is presented. Single-Cell In-Pile Test 509 (SCIP509) contained a vent in the emitter clad which allowed fission gases to pass into the interelectrode space. Single-Cell In-Pile Test 510 (SCIP-510) had a sealed emitter clad structure which contained fission gases within the clad. Layouts and photographs of the hardware, operational current-voltage characteristics, and postoperational results are presented.
\end{abstract}

\section{INTRODUCTION}

A significant decision in the design of a fission powered thermionic converter is the choice of method for accommodation of the fission product gases generated in the fueled emitter structure. It is the purpose of this paper to present the design and testing of two single-cell converter tests alike in all significant design features, except in the handling of the fission product gases. Single-Cell In-Pile Test 509 (SCIP-509) contained a vent in the emitter clad which allowed the fission gases to pass into the interelectrode space; Single-Cell In-Pile Test 510 (SCIP-510) had a sealed emitter clad structure which contained the fission gases within the clad. The extended operation of these two converters allows at least a qualitative comparison between the operation of vented and non-vented converter configuration.

A discussion of the design of the SCIP converters, the testing environment and method of testing, the operational results, and finally post-operational examination allow a framework from which the qualitative comparison can be made. To aid in the clarity of presentation, the SCIP-510 test is reviewed first.

*This work was performed for the Atomic Energy Commission under Contract No. A T (04-3)-189, P.A. 32 . 
Construction details of SCIP-510 are shown in Figure 1. At the left is a cut-away drawing of the complete converter. At the center is an enlarged view of the active diode region, while at the far right is a photograph of the emitter.

The emitter was fueled with uranium dioxide in the form of a cored pellet. This pellet was enclosed in a tungsten emitter clad. The vapor-deposited tungsten cylinder was sealed at both ends by electron beam welding vacuum arc cast tungsten caps in place. To one of these end caps, a tungsten pin was attached to stranded copper wire which led to the support post in a metal-to-ceramic seal assembly. The spacing of the emitter from the nickel collector was accomplished by the use of small tungsten pins imbedded in a molybdenum ring, which in turn was supported by a pair of alumina insulators placed in a machined groove in the collector. Identical assemblies were located at each end of the emitter. The cesium reservoir assembly contained one gram of liquid cesium. The nickel collector assembly was welded to the ceramic-to-metal seal assembly by a nickel to Inconel weld. Electric output of the thermionic converter appeared across the metal-to-ceramic seal.

Encapsulation of the converter and installation in the test reactor are shown in Figure 2. At the left is a photograph of the encapsulated converter without its outer capsule can, which is shown in the photograph at the center. At the far right is a schematic drawing of the capsule installation in the reactor.

The collector heat distributor, electric trim heater, and the variation of heliumargon gas mixture in the capsule permitted temperature control of the collector during operation. A similar arrangement of heat distributor, heater, and gas gap controlled the cesium reservoir temperature. The irradiation capsule was located in a positioning device next to the active core and just outside the pressure vessel of the irradiation reactor. This arrangement allowed variation of converter power input by movement of the converter toward and away from the reactor core. A flexible metal hose, containing instrumental and power leads, connected the capsule to a control console.

SCIP-510 was originally installed in the test reactor during March, 1966. During insertion, a slow rise to power was made to permit acquisition of current-voltage 
characteristics over a wide range of test conditions. After reaching the life test output of six watts per square centimeter, current-voltage characteristics were again taken. Throughout the test period of 3,596 hours, current-voltage characteristics were obtained approximately every 200 hours. Input power was somewhat variable due to reactor operation and method of test control. Emitter temperature was inferred by the examination of the I-V characteristics and their comparison with out-of-reactor tests of similar converters. Figure 3 presents I-V characteristics measured very soon after the start of test and shortly before the test ended. It is seen that for essentially the same emitter and cesium reservoir temperatures, the characteristics of the diode remained unchanged throughout the course of the testing.

After 3,596 hours of testing, a short circuit appeared between the emitter and collector. The site of the short circuit was examined in a hot cell, and the emitter was found to be bulged by about 0.007 -inch at the maximum. No detectable fission products were found external to the tungsten emitter, thus documenting the leak tightness of the tungsten clad throughout the operation. The results of the measurements in the hot cell are consistent with the hypothesis that the fission gas pressure internal to the tungsten clad had caused creep in the tungsten wall, such that the tungsten eventually shorted to the nickel collector. Analytical calculations based on approximately $100 \%$ release of fission gases and using available creep data for tungsten corroborate the hypothesis.

SCIP-509

SCIP-509 was essentially identical to the SCIP-510 described in the preceding except for the design of the emitter structure itself. A vent in one end of the emitter allowed the fission gases to escape into the interelectrode spaces while containing the $\mathrm{UO}_{2}$ fuel in the tungsten emitter. The diameter of the vent (Figure 4) was 0.020-inch.

The operation of SCIP-509 was similar in all important aspects to that of SCIP-510. The device operated in the reactor for 2,812 hours, at which time a leak in the envelope developed allowing gases from the capsule into the converter, and the converter was withdrawn from the reactor. The behavior of the converter was consistent with the hypothesis that the buildup of fission gases in the interelectrode space caused an increase in the thermal losses from the emitter, thereby reducing the efficiency of 
conversion. For constant load current and emitter temperature, an increase in input power of approximately $10 \%$ was required to overcome the increased thermal cooling effect of the fission gases. This effect increased asymptotically during the first 1,000 hours of operation and thereafter remained essentially constant. Thermionically, the major effect noted was a lowering of the optimum cesium reservoir temperature. Figure 5 shows comparative output characteristics from SCIP-510 and SCIP-509 at around the 2,700-hour operating time. It can be seen that SCIP-509 continued to produce comparable output but at lower cesium reservoir temperatures. From these characteristics it is seen that although the effect of the fission gases is certainly measurable, the overall effect is not large.

Upon disassembly of the converter in the hot cell, the emitter was measured to show no detectable change in dimensions and generally was in excellent condition. Figure 6 is a photograph of the SCIP-509 emitter as it appeared after operation. The vent hole can be seen in the end cap. No detectable amounts of uranium were found external to the emitter, and fission products other than the inert fission gases were present only in tract amounts. A total of 1.63 standard cubic centimeters of xenon plus krypton were found in the diode space. This corresponds to a pressure of 178 torr of pressure at operating temperature. Significantly, this is some 100 times the cesium pressure associated with the $290^{\circ} \mathrm{C}$ optimum cesium reservoir temperature.

\section{SUMMARY}

In conclusion, two in-pile thermionic tests have been operated for times of approximately 3,000 hours, one with a sealed emitter and one with a vented emitter. The sealed emitter test was terminated by the shorting of the emitter to the collector, probably due to creep of the tungsten clad caused by internal fission product gas pressure. The vented test was terminated due to a failure of the envelope, an independent event. The fission product gases were released from the emitter as intended. The $\mathrm{UO}_{2}$ fuel was contained in the emitter as intended, and the overall effect on the operation of the converter was hypothetically explained by the increased thermal losses from the emitter to the collector. 


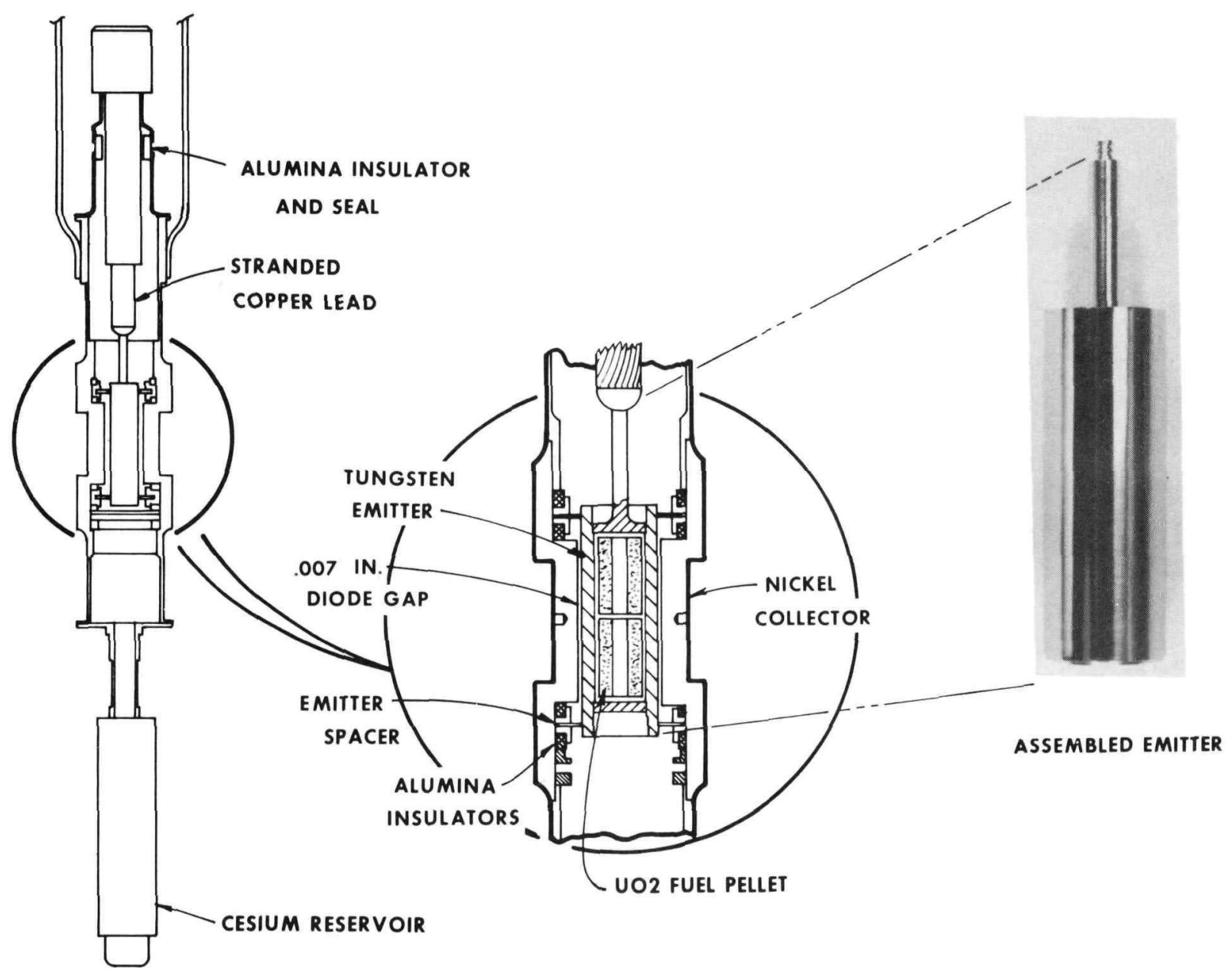

FIGURE 1 CONVERTER SCIP 510 


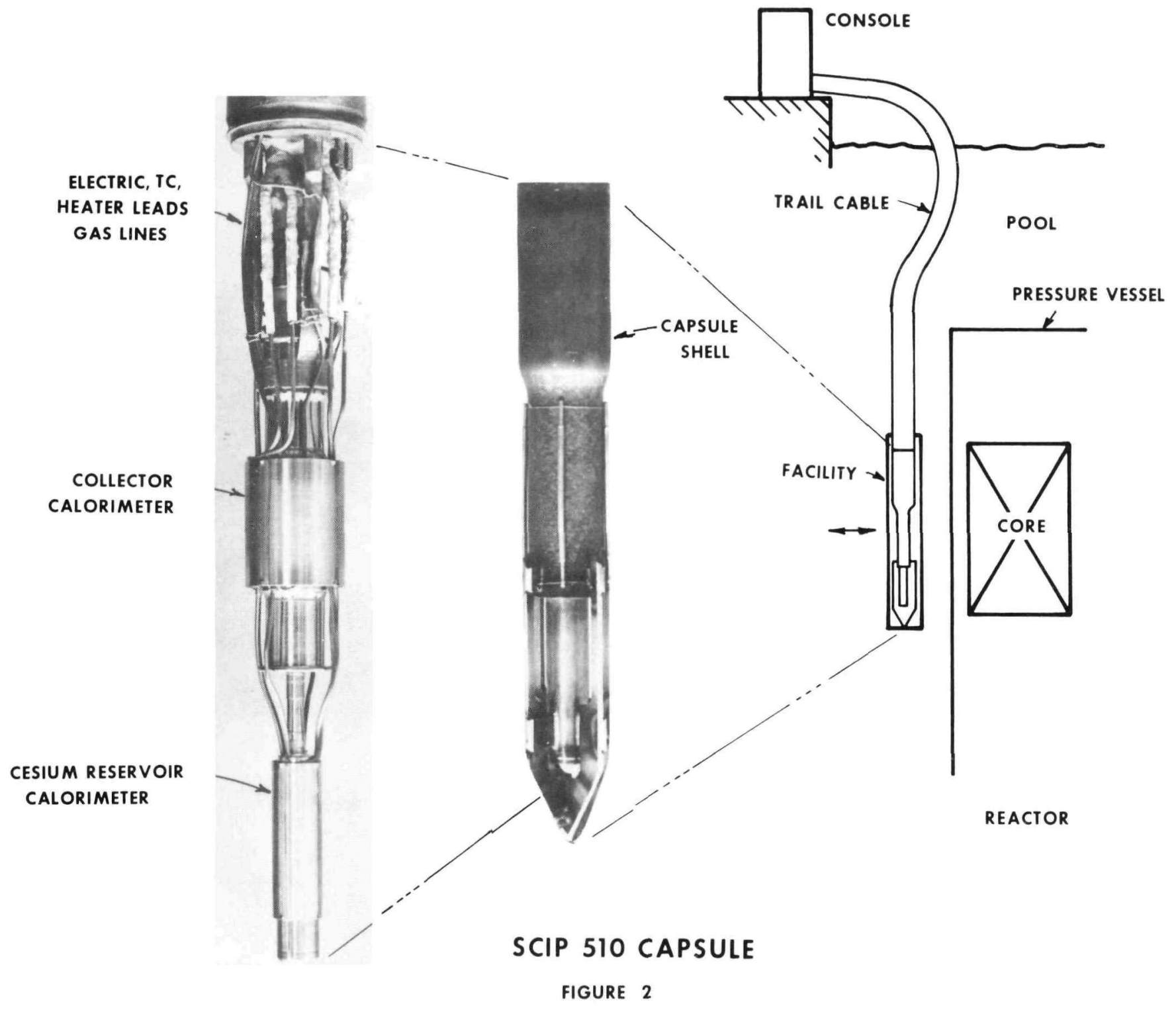




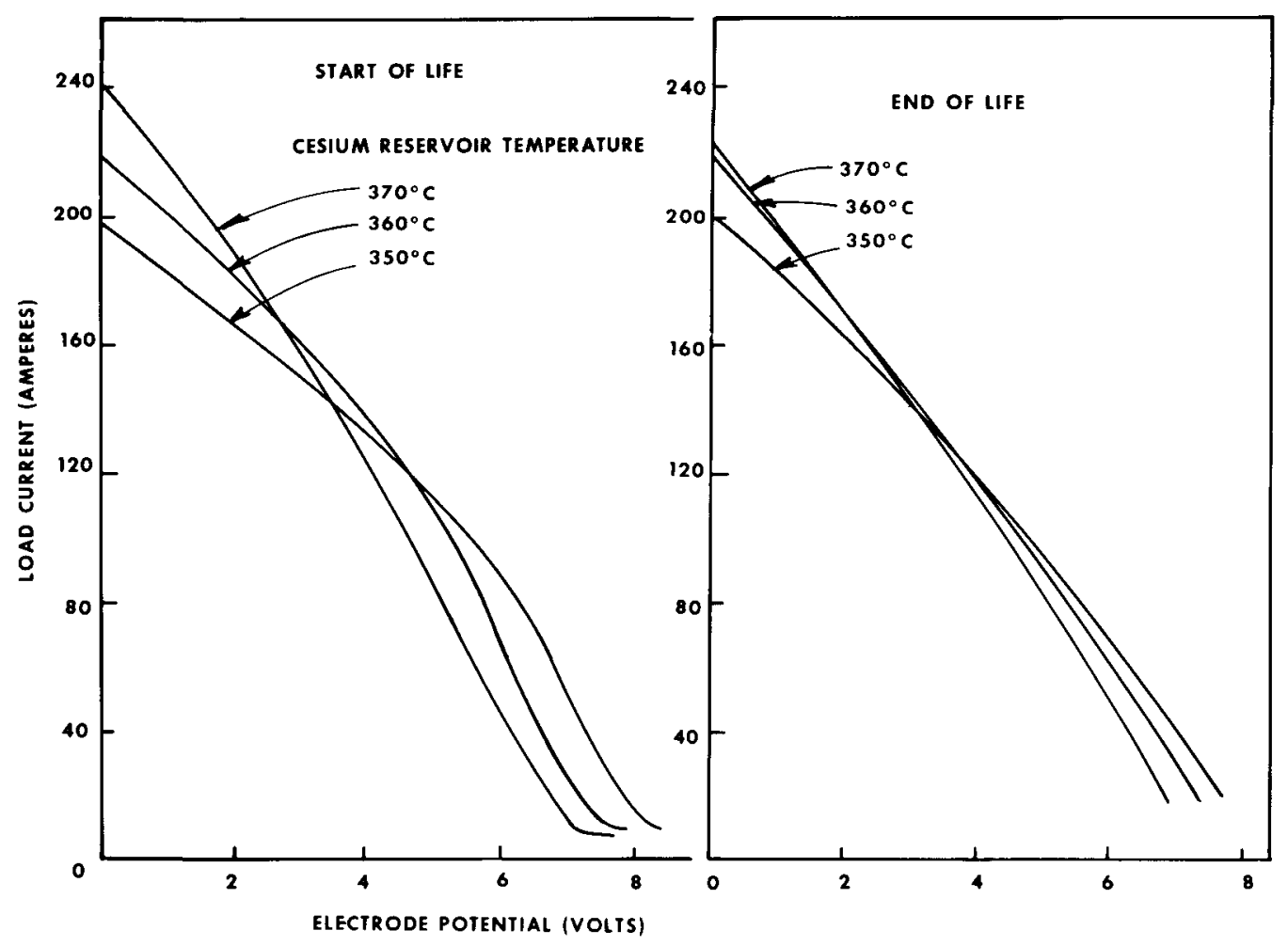

SCIP 510 OUTPUT CHARACTERISTICS

FIGURE 3

(FOR $1600^{\circ} \mathrm{C}$ EMITIER TEMPERATURE) 


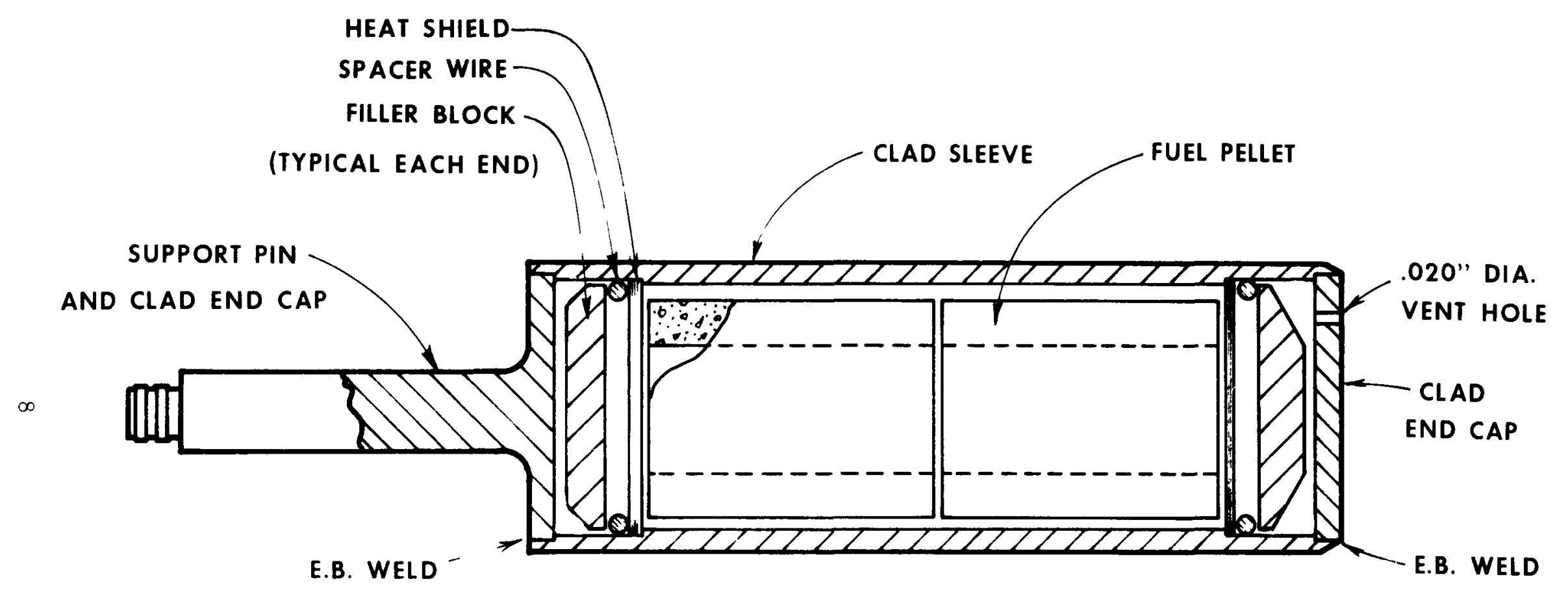




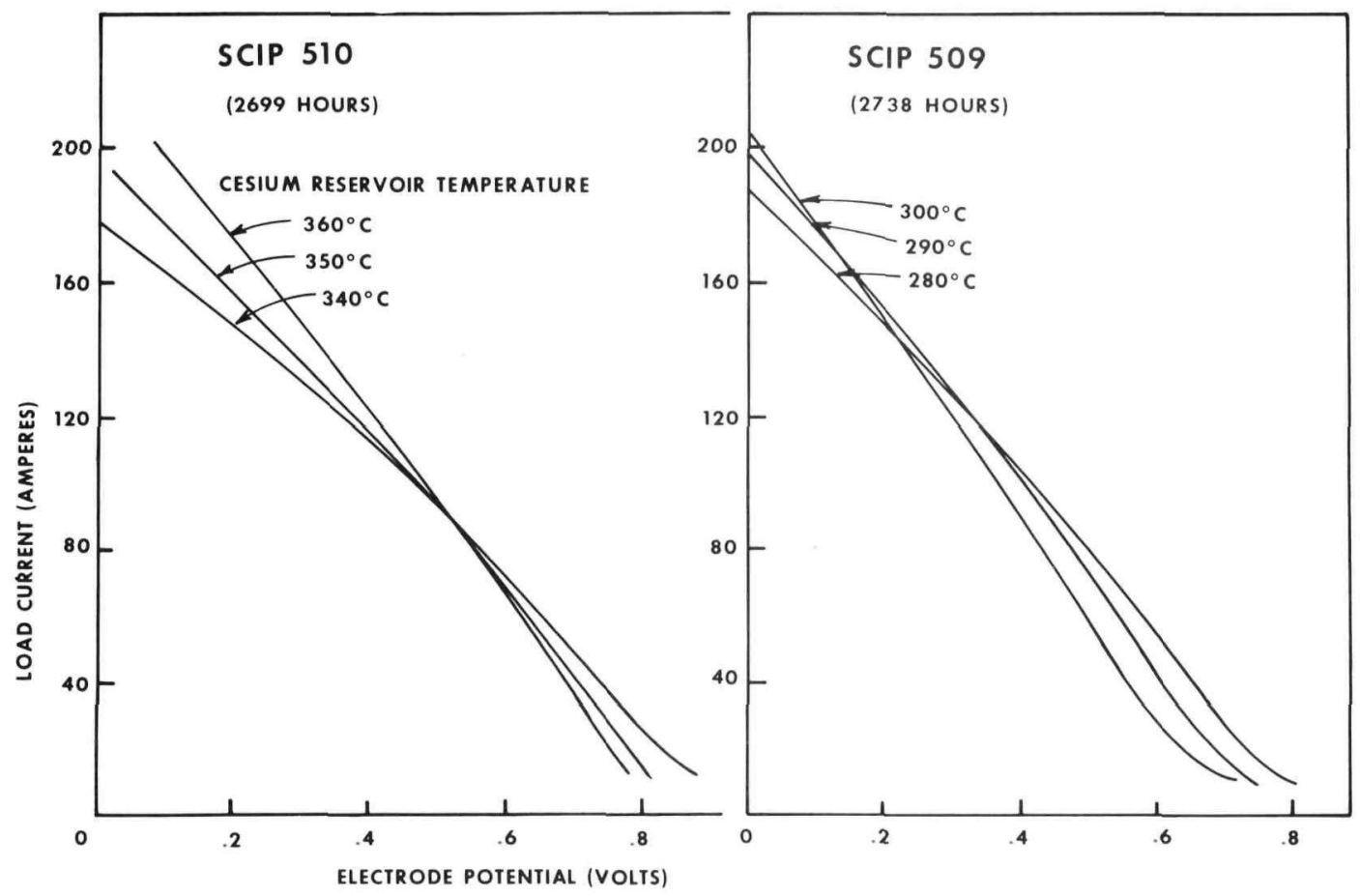

COMPARISON OF SCIP $510 \& 509$ OUTPUT CHARACTERISTICS FIGURE 5 (FOR $1600^{\circ} \mathrm{C}$ EMITIER IEMPERATURE)

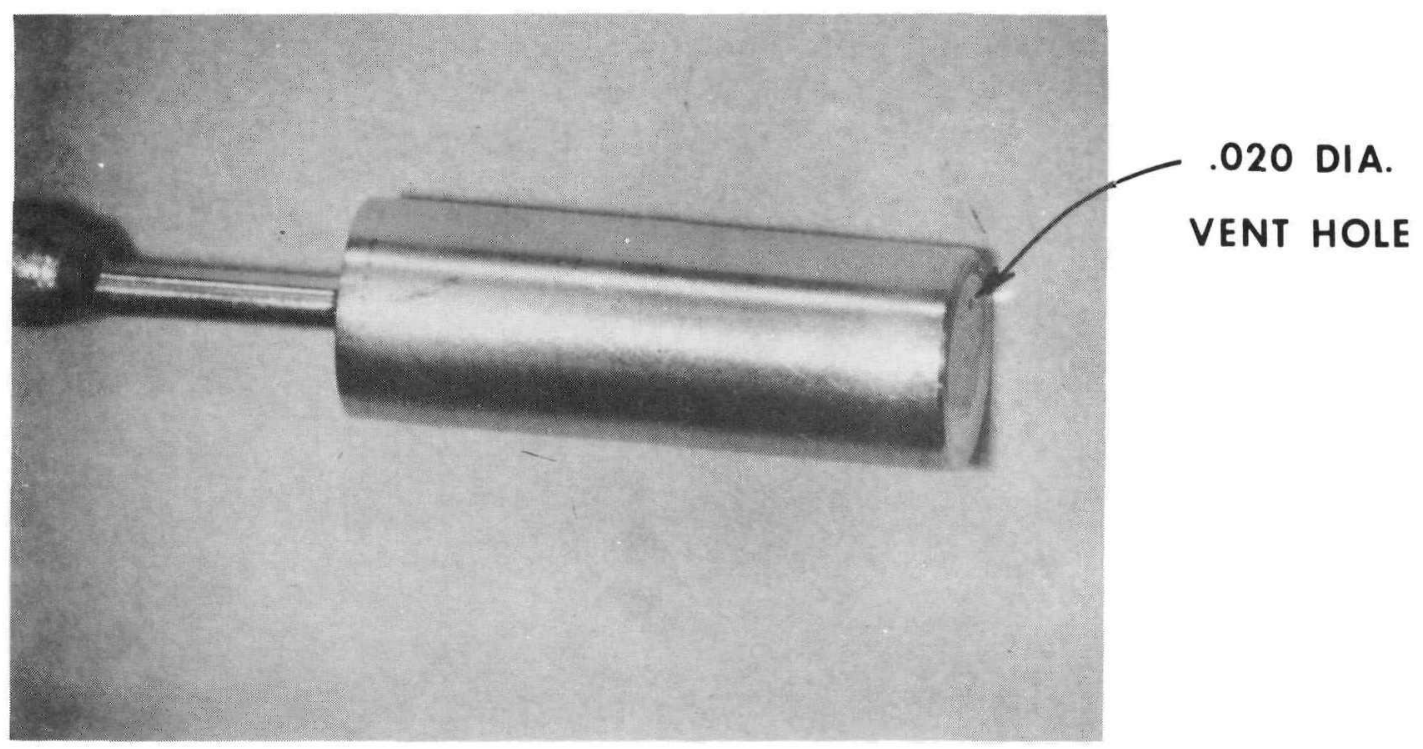

FIGURE 6 SCIP 509 EMITTER AFTER OPERATION

\section{HOURS}

CALCULATED BURNUP $2.2 \times 10^{20} \mathrm{~F} / \mathrm{CC}$ 